Revista Brasileira de Agricultura Irrigada v.10, nº.4, p. 809 - 819, 2016

ISSN 1982-7679 (On-line)

Fortaleza, CE, INOVAGRI - http://www.inovagri.org.br

DOI: $10.7127 /$ rbai.v10n400450

Protocolo 450.16 - 17/06/2016 Aprovado em 10/08/2016

\title{
APTIDÃO E ZONEAMENTO AGROCLIMÁTICO DA PALMA FORRAGEIRA PARA O ESTADO DO PIAUÍ
}

\author{
Daisy Beserra Lucena ${ }^{1}$, Raimundo Mainar de Medeiros², \\ Luciano Marcelo Fallé Saboya $^{3}$, Pedro Luiz do Nascimento ${ }^{4}$
}

\begin{abstract}
RESUMO
A aptidão e o zoneamento agroclimático são extraordinários processos de informação do potencial agrícola da palma forrageira para o estado do Piaú. Diante dessa afirmativa, o objetivo deste trabalho é caracterizar o clima e efetivar a aptidão e o zoneamento agroclimático da cultura na área em estudo. Os dados utilizados foram série histórica de precipitação, temperatura do ar (máxima, mínima e média) e amplitude térmica provenientes do Instituto Nacional de Meteorologia (INMET). O cálculo do balanço hídrico climatológico foi realizado para a capacidade de campo de $100 \mathrm{~mm}$, obtendo-se os índices de umidade, aridez e hídrico. As atividades fisiológicas da palma forrageira para o Estado do Piauí mostraram-se restritas devido às condições inadequadas da disponibilidade de temperatura e do índice de umidade, isto para todos os municípios, classificando-se dentro de faixa restrita ou inapta ao desenvolvimento da cultura. Entretanto, algumas localidades dentro do Estado apresentaram índices pluviométricos necessários ao desenvolvimento da palma forrageira. Sendo assim, fica claro que, para o plantio em larga escala é necessário um planejamento adequado para a utilização de cultivares mais resistentes às temperaturas e aos índices de umidade, e a adequação de sistema de irrigação eficiente e compatível com a demanda de água da cultura.
\end{abstract}

Palavras-chaves: Nordeste Brasileiro, Cultivos, forragem, Clima semiárido e Subúmido.

\section{APTITUDE AND AGROCLIMATIC ZONING OF PALMA FORRAGEIRA FOR THE PIAUI STATE}

\footnotetext{
ABSTRACT

${ }^{1}$ Prof. Dra. Departamento de geociência - Centro de Ciências Exatas e da Natureza - Universidade Federal da Paraíba, Paraíba - Brasil (daisylucena@yahoo.com.br)

${ }^{2}$ Doutor em Meteorologia, Universidade Federal de Campina Grande, Paraiba - Brasil (mainarmedeiros@gmail.com)

${ }^{3}$ Professor Doutor do Curso de Engenharia Agrícola, Universidade Federal de Campina Grande, Paraíba - Brasil

${ }^{4}$ Prof. mestre, UAFÍSICA/CCT/UFCG, Campina Grande-PB, Brasil. pedroln@df.ufcg.edu.br
} 
The aptitude and agroclimatic zoning are extraordinary information processes of the agricultural potential of forage cactus to the state of Piauí. Given this statement, the aim of this study is to characterize the climate and carry out aptitude and agroclimatic zoning of culture in the study area. The data were time series of precipitation, air temperature (maximum, minimum and average) and temperature range from the National Institute of Meteorology (INMET). The calculation of the climatic water balance was carried out for 100 $\mathrm{mm}$ field capacity, obtaining the humidity levels, drought and water. The physiological activities of the forage palm Piaui state proved limited due to inadequate conditions of availability of temperature and moisture content, that for all municipalities and are classified within restricted or unsuited track the development of culture. However, some scattered within the state showed rainfall necessary for the development of the cactus pear. Thus, it is clear that for the large scale cultivation is required proper planning for the use of materials more resistant to the temperatures and moisture contents, and the suitability of efficient and compatible irrigation system with the demand for water culture.

Keywords: Brazilian Northeast, crops, fodder, semi-arid climate and sub-humid areas.

\section{INTRODUÇÃO}

Embora possua uma reconhecida gama de potencialidades, a palma forrageira tem sido cultivada no Semiárido Brasileiro quase exclusivamente para a produção de forragem (SANTOS et al., 2001; ARAÚJO e OLIVEIRA, 2005; PINTO et al., 2011) e de acordo com Bezerra et al. (2014) se tornou, ao longo das décadas, uma das principais alternativas para alimentação dos rebanhos, sobretudo em longos períodos de estiagem, quando as pastagens nativas e outras forrageiras, tais como as gramíneas e leguminosas de elevada exigência hídrica, estão sob fortes condições de estresse hídrico.

No entanto, na maioria dos cultivos da palma forrageira têm sido dispensadas, à região, maiores preocupações em manejos e tratos culturais básicos. Em outras palavras, a palma forrageira nunca foi encarada como lavoura. Entretanto e de acordo com Moura et al. (2011) a palma forrageira, tal como outra cultura qualquer, não dispensa tratos culturais básicos, tais como fertilização, controle de plantas daninhas, doenças e pragas, como a cochonilha de escama (Pinnaspis aspidistrae) e a cochonilha-do-carmim (Dactylopius opuntiae) além do delineamento de densidade de plantio adequado para expressar seu potencial produtivo.

A Palma é considerada uma importante aliada na sustentabilidade e na redução da vulnerabilidade das atividades agropecuárias no Semiárido Brasileiro (MOURA et al., 2011). Ainda de acordo com os autores, embora se tenha referência na literatura sobre as condições climáticas favoráveis ao cultivo da palma forrageira por se tratar de uma cultura com grandes oportunidades de adaptabilidade às condições de semiaridez, seu cultivo tem sido realizado sem que haja um embasamento técnico-científico no que concerne às suas necessidades climáticas.

A aptidão climática destina-se a caracterizar os parâmetros meteorológicos que mais atuam no comportamento das culturas e, que em suas condições extremas, venham a prejudicar sensivelmente o crescimento e desenvolvimento da planta em conformidade com Ometto (1981).

No Nordeste Brasileiro que, frequentemente, enfrenta os problemas da seca, estiagens, alagamentos e inundações prolongadas dentro do período chuvoso, estas condições se tornam ainda mais graves pois afetam toda a parte social e econômica da região. (NOBRE e MELO, 2001; MARENGO, 2009; KAYANO e ANDREOLI, 2009; MARENGO et al., 2011). Em se tratando do fenômeno seca, esse é uma problemática que causam diversos setores para essa região que apresenta uma grande irregularidade de precipitação, causando inúmeros transtornos à população, um deles é a escassez de água para as mais diversas utilidades. Atualmente, as 
previsões com base no impacto das mudanças climáticas sobre os recursos hídricos, ameaçam intensificar a dificuldade de acesso à água, tendo em vista que a região já enfrenta problemas crônicos de falta d'água (MARENGO et al., 2011). Os autores ainda relatam que isto impactará significativamente na agricultura de subsistência, agropecuária, indústria, geração de energia e irrigação, saúde humana, etc. Dessa forma, uma das metodologias para analisar a deficiências ou excesso de água ao longo do ano, segundo Camargo (1971) e Horikoshi e Fisch (2007), é necessária comparar dois termos contrários do balanço, a precipitação (responsável pela umidade para o solo) e a evapotranspiração que utiliza essa umidade do solo. Segundo Pereira et al. (2002) e Horikoshi e Fisch (2007), a água disponível para o consumo e uso do homem pode ser quantificada pelo balanço hídrico climatológico, em que fica evidente a variação temporal de períodos com excedente e com deficiência hídricas, permitindo, dessa forma, o planejamento agrícola. $\mathrm{O}$ mapeamento de variáveis que compõem o balanço hídrico é fundamental para o planejamento de técnicas do uso da terra e para entender, explicar e prever o crescimento e o desenvolvimento dos recursos naturais, com a finalidade de promover a sua utilização racional.

Diante do exposto, o conhecimento do comportamento das variáveis climáticas é de suma importância para o planejamento das atividades agrícolas. Não obstante, a temperatura do ar destaca-se na condução de estudos concernentes à ordenação agrícola, uso do solo, zoneamento ecológico e aptidão climática, época de semeadura, estimativa do ciclo das culturas, dentre outras conforme Oliveira Neto et al. (2002).

Nesse contexto, o objetivo deste trabalho é realizar a aptidão e o zoneamento agroclimático para a cultura da palma forrageira (Opuntia sp.) para o estado do Piauí.

\section{MATERIAL E MÉTODOS}

O Piauí é um estado localizado na parte oeste do Nordeste Brasileiro, com uma área de
$252.385 \mathrm{Km}^{2}$, representando 2,95\% do total do território nacional. Suas maiores altitudes são registradas no platô da Serra das Mangabeiras, com 880 metros acima do nível do mar. As maiores distâncias (em linha reta) são 887 Km de norte a sul e $618 \mathrm{Km}$ de leste a oeste. Limita-se ao norte com o Oceano Atlântico, ao sul com os estados da Bahia e Tocantins, ao leste com o Ceará e Pernambuco e ao oeste com o Maranhão. Tendo como pontos extremos: ao norte, a ponta setentrional da Ilha Grande de Santa Isabel; ao sul, o divisor de águas dos Rios Paraim e Preto (Piauí/Bahia); ao leste, divisor de águas dos cursos Riachão e Riacho Conceição e ao oeste, a curva do Rio Parnaíba, entre os afluentes da margem esquerda, Rio da Pedra Ferrada e Rio Medenho. O Estado é composto por 225 municípios (CONDEPI, 2000).

Para a análise do comportamento climático do estado do Piauí utilizou-se dados de precipitação fornecidos pela Superintendência do desenvolvimento do Nordeste (SUDENE) e da Empresa de Assistência Técnica e Extensão Rural do Estado do Piauí (EMATER-PI). A estimativa da temperatura do ar para o período de 1950 a 2011 com base em 137 postos pluviométricos localizados por todo o Estado.

A estimativa da temperatura média do ar foi realizada pelo software denominado "Estima_T" (CAVALCANTI et al., 2006), desenvolvido pelo Núcleo de Meteorologia Aplicada da Universidade Federal de Campina Grande (UFCG). O “Estima_T” é um software para fazer estimativas de temperaturas do ar na região NEB. A região foi dividida em três áreas: 1 - Maranhão e Piauí; 2 - Ceará, Rio Grande do Norte, Paraíba e Pernambuco e 3 Alagoas, Sergipe e Bahia. Para cada uma das regiões se determinaram os coeficientes da função quadrática para as temperaturas média, máxima e mínima mensal, em função das coordenadas locais: longitude, latitude e altitude em conformidade com Cavalcanti et al. (2006).

O modelo empírico de estimativa da temperatura do ar é uma superfície quadrática, dada pela equação 1. 


$$
\mathrm{T}_{\mathrm{ij}}=\mathrm{C}_{0}+\mathrm{C}_{1} \lambda+\mathrm{C}_{2} \varnothing+\mathrm{C}_{3} \mathrm{~h}+\mathrm{C}_{4} \lambda^{2}+\mathrm{C}_{5} \varnothing^{2}+\mathrm{C}_{6} \mathrm{~h}^{2}+\mathrm{C}_{7} \lambda \varnothing+\mathrm{C}_{8} \lambda \mathrm{h}+\mathrm{C}_{9} \varnothing \mathrm{h}+\mathrm{ATSM}_{\mathrm{ij}}
$$

Em que: $\mathrm{C}_{0}, \mathrm{C}_{1}, \ldots ., \mathrm{C}_{9}$ são constantes (coeficientes); $\lambda$ é a longitude e $\varnothing$ a latitude, em graus, e $\mathrm{h}$ altura(metros). Os índices $\mathrm{i}$ e $\mathrm{j}$ indicam, respectivamente, o mês e o ano para os quais se está calculando a temperatura do ar $\left(\mathrm{T}_{\mathrm{ij}}\right)$.

Assim, o sinal das Anomalias de Temperaturas da Superfície do Mar (ATSM), ATSM $_{\mathrm{ij}}$, assume valores positivos e negativos, de acordo com o padrão de comportamento da TSM do oceano. Cavalcanti et al. (2006) também utilizaram uma superfície quadrática para determinar as temperaturas médias e extremas no NEB e, expressa, porém, apenas em função das coordenadas geográficas.

Pode-se estimar a série temporal de temperatura, adicionando-lhe a anomalia de temperatura do Oceano Atlântico Tropical (SILVA et al.,2006), conforme a equação 2.

$$
\mathrm{T}_{\mathrm{ij}}=\mathrm{T}_{\mathrm{i}}+\mathrm{AAT}_{\mathrm{ij}}
$$

Sendo $\quad \mathrm{i}=1,2,3, \ldots, 12$ e $\mathrm{j}=$ 1926,1927,1928,...,2015.

O cálculo do balanço hídrico climatológico (BHC) foi realizado através da metodologia proposta por Thornthwaite e
Mather (1955), com elaboração de planilhas eletrônicas em conformidade com Medeiros (2014) que contabilizam as entradas e saídas de água no solo, em que a precipitação representa (ganho) e a evapotranspiração (perda) de umidade do solo, podendo-se estimar os valores correspondentes ao Excedente Hídrico (EXE) e Deficiência Hídrica (DEF). Com base nesta metodologia foi estimada a capacidade de armazenamento de água disponível no solo (CAD) de $100 \mathrm{~mm}$. A Evapotranspiração Potencial (ETp) foi obtida conforme a equação 3 .

$$
E T p=F_{C} \cdot 16 \cdot\left(10 \frac{T}{I}\right)^{a}
$$

Em que;

ETp - Evapotranspiração potencial anual (mm ano $^{-1}$ );

Fc - Fator de correção, segundo a Tabela 1;

$\mathrm{T}$ - Temperatura média mensal $\left({ }^{\circ} \mathrm{C}\right)$;

I - Índice anual de calor, correspondente a

soma dos doze índices mensais; e

a - Função cúbica do índice anual de calor dada pela

equação

4:

$$
\mathrm{a}=6,75 * 10^{-7} * \mathrm{I}^{3}-7,71 * 10^{-5} * \mathrm{I}^{2}+0,01791 * \mathrm{I}+0,492
$$

$\mathrm{Na}$ determinação da aptidão climática para a cultura da palma forrageira (Opuntia sp.), foram utiliza dos os indicadores climáticos propostos por Souza et al. (2008) e expostos na Tabela 2. Essas faixas foram utilizadas no estudo do zoneamento agroclimático da palma forrageira para o estado de Pernambuco por Moura et al. (2011) e por Bezerra et al. (2014) e também em estudo sobre o zoneamento agroclimático da palma forrageira para o estado da Paraíba

Tabela 1. Fator de Correção de acordo com Thornthwaite e Mather (1955) em função de todos os meses do ano.

\begin{tabular}{llllllllllll}
\hline \multicolumn{10}{c}{ Fator de Correção } \\
\hline Jan & Fev & Mar & Abr & Mai & Jun & Jul & Ago & Set & Out & Nov & Dez \\
1,08 & 0,97 & 1,05 & 0,99 & 1,01 & 0,96 & 1,00 & 1,01 & 1,00 & 1,06 & 1,05 & 1,10 \\
\hline
\end{tabular}

Fonte: UNESCO (1982).

Por meio do balanço hídrico, calcularam-se os índices de aridez, umidade e hídrico. Estes índices são importantes para a caracterização climática da região segundo a metodologia de Thornthwaite (1948), e no estudo de adaptação de culturas à região (Zoneamento Agroclimático). 
O Índice de Aridez caracteriza-se por indicar a deficiência hídrica expressa em percentagem da evapotranspiração potencial (necessidade). É definido em função da deficiência e evapotranspiração potencial (ambas anuais), expresso pela equação 5 .

$$
I a=100 \frac{\sum D E F}{\sum E T p}
$$

O índice de umidade representa o excesso hídrico expresso em percentagem da necessidade que é representada pela evapotranspiração potencial, ambas anuais, segundo a expressão 6 .

$$
I h=100 \frac{\sum E X E}{\sum E T p}
$$

Geralmente tem-se durante 0 ano estações de excesso e falta de água. Por isso, define-se o índice hídrico pela equação 7.

$$
I u=I h-0,6 \cdot I a
$$

Em que:

Ia - Índice de aridez (\%);

Ih - Índice hídrico (\%);

Iu - Índice de umidade (\%);

$\sum$ DEF - Somatório da deficiência hídrica anual $\left(\mathrm{mm} \mathrm{ano}^{-1}\right)$;

$\sum$ EXE - Somatório do excedente hídrico anual $\left(\mathrm{mm} \mathrm{ano}^{-1}\right)$; e

$\sum$ ETp - Somatório da evapotranspiração anual $\left.(\mathrm{mm} \mathrm{ano})^{-1}\right)$.

Os valores dos indicadores climáticos para o estado do Piauí foram aplicados em conformidade a Tabela 2 para determinação da aptidão climática, classificando a cultura da palma forrageira em aptidão plena, aptidão restrita e aptidão inaptidão.

Tabela 2. Aptidão e indicadores climáticos da cultura da palma forrageira.

\begin{tabular}{ccc}
\hline Plena & Restrita & Inaptidão \\
\hline 16,1 $\leq$ Tméd $\leq 25,4$ & Tméd $<16,1 ;$ Tméd $>25,4$ & - \\
28,5 $\leq$ máx $\leq 31,5$ & Tmáx $<28,5 ;$ Tmáx $>31,5$ & - \\
$8,6 \leq$ Tmín $\leq 20,4$ & Tmín $<8,6$; Tmín $>20,4$ & - \\
$10,0 \leq$ AMT $\leq 17,2$ & AMT $<10,0 ;$ AMT $>17,2$ & - \\
368,4 $\leq$ Prec $\leq 812,4$ & Prec $<368,4 ; 812,4<$ Prec $\leq 1089,9$ & Prec $>1089,9$ \\
$-65,6 \leq$ Iu $\leq-31,8$ & $-31,8<$ I $\leq 7,7$; Iu $<-65,6$ & Iu $>7,7$ \\
\hline
\end{tabular}

Fonte: Souza et al. (2008)

Tméd=Temperatura média; Tmáx=Temperatura máxima; Tmín=Temperatura mínima; AMT=Amplitude térmica; Prec=Precipitação média anual; Iu=Índice de umidade; (-) sem informações.

Para a aptidão e zoneamento agroclimático utilizou-se dos critérios para classificação descritos por Moura et al. (2011) e referenciado por Bezerra et al. (2014), da seguinte forma:

- Plena: A região possui clima adequado ao desenvolvimento da cultura, sem apresentar nenhuma restrição ao crescimento e desenvolvimento da cultura.

- Restrita: O cultivo da palma forrageira nesta região é limitado no mínimo por um dos indicadores climáticos.

- Inaptidão: Nesta região os indicadores climáticos encontram-se fora das faixas adequadas ao desenvolvimento da cultura.

\section{RESULTADOS E DISCUSSÃO}

Observam-se na Tabela 3 os resultados obtidos e as variáveis utilizadas para a elaboração da aptidão e do zoneamento agroclimático e na determinação do balanço hídrico climatológico do estado do Piauí considerando a capacidade de armazenamento de água disponível (CAD) de $100 \mathrm{~mm}$.

A temperatura média anual do estado é de $25,9^{\circ} \mathrm{C}$, com os menores valores ocorridos em fevereiro com temperaturas de $24,9^{\circ} \mathrm{C}$ e a máxima de $27,8{ }^{\circ} \mathrm{C}$ no mês de outubro. As temperaturas máximas, também coerentes com as médias, apresentam seu menor valor no mês 
de fevereiro $\left(30,9^{\circ} \mathrm{C}\right)$ e a máxima em outubro $\left(35,4^{\circ} \mathrm{C}\right)$. A temperatura mínima oscilou entre $19,5^{\circ} \mathrm{C}$ no mês de julho a 22 ${ }^{\circ} \mathrm{C}$ em novembro.

Tabela 3. Variáveis utilizadas na elaboração da aptidão e do zoneamento agroclimático e na determinação do balanço hídrico climatológico.

\begin{tabular}{|c|c|c|c|c|c|c|c|c|c|c|c|}
\hline \multirow[t]{14}{*}{ Legenda: } & \multirow{2}{*}{ Meses } & Tméd & Tmáx & Tmín & AMT & Prec & ETp & $\mathrm{EVr}$ & DEF & EXC & \multirow[t]{2}{*}{ Tméd } \\
\hline & & \multicolumn{4}{|c|}{$\left({ }^{\circ} \mathrm{C}\right)$} & \multicolumn{5}{|c|}{$(\mathrm{mm})$} & \\
\hline & Jan & 25,4 & 31,8 & 21,5 & 9,8 & 124,8 & 119,8 & 119,8 & 0,0 & 0,0 & \\
\hline & Fev & 24,9 & 30,9 & 21,5 & 8,9 & 124,9 & 103,5 & 103,5 & 0,0 & 0,0 & \\
\hline & Mar & 25,2 & 31,6 & 21,3 & 9,8 & 169,9 & 118,1 & 118,1 & 0,0 & 0,0 & \\
\hline & Abr & 25,2 & 31,3 & 21,3 & 9,5 & 119,8 & 112,6 & 112,6 & 0,0 & 0,0 & \\
\hline & Mai & 25,2 & 31,8 & 20,7 & 10,4 & 43,2 & 114,7 & 86,9 & 27,8 & 0,0 & \\
\hline & Jun & 25,1 & 32,3 & 19,7 & 12,0 & 11,6 & 108,3 & 37,5 & 70,8 & 0,0 & \\
\hline & Jul & 25,3 & 33,0 & 19,5 & 12,8 & 3,7 & 114,9 & 14,4 & 100,5 & 0,0 & \\
\hline & Ago & 26,2 & 34,4 & 19,9 & 13,9 & 1,6 & 131,0 & 5,4 & 125,6 & 0,0 & \\
\hline & Set & 27,5 & 35,5 & 21,3 & 13,5 & 4,7 & 152,5 & 5,8 & 146,7 & 0,0 & \\
\hline & Out & 27,8 & 35,4 & 21,9 & 12,8 & 17,2 & 166,3 & 17,5 & 148,8 & 0,0 & \\
\hline & Nov & 27,2 & 34,6 & 22,0 & 11,9 & 46,1 & 151,1 & 46,1 & 104,9 & 0,0 & \\
\hline & Dez & 26,2 & 33,0 & 21,8 & 10,7 & 75,2 & 138,0 & 75,2 & 62,8 & 0.0 & \\
\hline
\end{tabular}

Temperatura média; Tmáx - Temperatura máxima; Tmín - Temperatura mínima; AMT - Amplitude térmica, Prec Precipitação média anual; ETp - Evapotranspiração potencial, EVr - Evapotranspiração real, DEF - Deficiência hídrica e EXC - Excesso Hídrico.

O trimestre correspondente aos meses de fevereiro, março e abril, apresentou os menores valores de amplitude térmica, já os meses de julho, agosto e setembro proporcionam as maiores amplitudes térmicas. A amplitude térmica média anual é de $11,3{ }^{\circ} \mathrm{C}$, sendo o menor valor de $8,9{ }^{\circ} \mathrm{C}$ registrado no mês de fevereiro e a maior de $13,9{ }^{\circ} \mathrm{C}$ no mês de agosto, resultados concordantes com o trabalho de Medeiros et al. (2013).

O estado do Piauí tem distribuição pluviométrica anual irregular com média anual de $742,7 \mathrm{~mm}$, sendo as maiores precipitações ocorridas entre os meses de janeiro e abril, oscilando de 124,8 a 169,9 mm, correspondendo aos meses com maiores índices pluviométricos. Os menores índices pluviométricos ocorrem nos meses de junho a outubro, com oscilações de 1,6 a 17,2 mm. Estes resultados estão em conformidade com os obtidos no estudo sobre o regime da precipitação no estado do Piauí, realizado por Medeiros (2013).

O período chuvoso corresponde aos meses de novembro a abril, e os meses de julho a setembro correspondem aos meses secos. Medeiros et al. (2015) descrevem que as precipitações ocorridas de junho a setembro são caracterizadas como abaixo da evapotranspiração, não sendo suficiente para atender a demanda ocorrida no período, tornando inviável a produção agrícola de sequeiro e com pouca contribuição para o armazenamento de água no solo. Guerra et al. (2005) constataram que os genótipos da palma forrageira e suas variedades miúda, redonda e gigante, apresentaram maior rendimento nas regiões com precipitação pluviométrica média de 700,0 mm ano ${ }^{-1}$. Segundo Rocha (2012), a faixa adequada de precipitação pluviométrica ao desenvolvimento da palma forrageira está entre 368,4 e 812,4 mm, embora possa ser cultivada com $200 \mathrm{~mm}$.

A evapotranspiração potencial anual tem o seu somatório de $1.579,9 \mathrm{~mm}$ ano $^{-1}$, com oscilações de 103,5 a 166,3 mm mês ${ }^{-1}$. A evaporação real (EVr), que representa a quantidade real de água evaporada, se comportou de forma semelhante à distribuição mensal da precipitação pluvial. A maior média anual de ETp obtida pode está associada ao método utilizado para a estimativa da evapotranspiração, que pode ter superestimado os valores de ETp.

Verificou-se que nos meses de maio a dezembro ocorrem os maiores déficits hídrico, 
variando de 27,8 a 148,8 mm mês ${ }^{-1}$, com um total médio anual de $788 \mathrm{~mm}$. Durante os meses não ocorrem excedente hídricos.

Para certificar-se de uma melhor produtividade das culturas, é indispensável o uso de sistemas de irrigação em regiões que apresentam deficiência hídrica que limitar o desenvolvimento das culturas, principalmente quando esta deficiência se estende por todos os meses do ano (SANTOS et al., 2010).

Conforme Marengo et al. (2004) é de suma importância o conhecimento do comportamento da deficiência hídrica em uma localidade, principalmente para o planejamento agrícola, para que o desenvolvimento seja seguro e economicamente viável, e se necessário utilizar da prática de sistemas de irrigação. Além do déficit hídrico, é importante entender as variáveis climáticas da região, analisando cuidadosamente a variabilidade da precipitação e a intensidade da evapotranspiração.

Através do balanço hídrico climatológico determinaram-se os índices de aridez (Ia), hídrico (Ih) e de umidade (Iu) para o estado do Piauí, conforme Tabela 4.

Tabela 4. Índices: aridez, hídrico e umidade para o estado do Piauí.

\begin{tabular}{ccc}
\hline Ia (\%) & Ih (\%) & Iu (\%) \\
\hline 51,48 & 0,51 & $-0,31$ \\
\hline
\end{tabular}

Wollmann e Galvani (2013) relatam que as condições locais hídricas e de clima, são levadas em consideração no zoneamento agroclimático, visando à exploração de culturas economicamente rentáveis. São estas as características agroclimáticas desta localidade que determinam a aptidão ao desenvolvimento das culturas.

A aptidão e o zoneamento da palma forrageira para o estado do Piauí foram realizadas baseando-se nos resultados obtidos na tabela 3 e 4 comparando-as com as condições exigidas pela cultura conforme Tabela 2.
Analisando os resultados percebe-se claramente que a cultivar é bem restrita a região de estudo, principalmente tratando-se dos elementos temperatura e índice de umidade. Quanto a precipitação apesar de a mesma apresentar irregularidade, mesmo assim em algumas localidades tem-se aptidão plena ao cultivo da palma forrageira (vide Tabela 5). Segundo Toledo et al. (2009) a aptidão climática de uma região é determinada com base na agregação da precipitação, temperatura e altitude local, sendo de grande importância sob o aspecto própria das culturas, geradora de recursos a agricultura.

Tabela 5. Classificações de aptidões e zoneamento para temperatura, precipitação e índices de umidade para a Palma forrageira no estado do Piauí.

\begin{tabular}{|c|c|c|c|c|c|c|c|}
\hline Município & $\begin{array}{l}\text { Classificação } \\
\text { Temperatura }\end{array}$ & $\begin{array}{c}\text { Classificaçã } \\
\text { o } \\
\text { Precipitação }\end{array}$ & $\begin{array}{l}\text { Classificação } \\
\text { Índice de } \\
\text { Umidade }\end{array}$ & Município & $\begin{array}{l}\text { Classificação } \\
\text { Temperatura }\end{array}$ & $\begin{array}{l}\text { Classificação } \\
\text { Precipitação }\end{array}$ & $\begin{array}{c}\text { Classificação } \\
\text { Índice de } \\
\text { Umidade }\end{array}$ \\
\hline Acauã & Restrita & Plena & Restrita & Colônia G. & Restrita & Plena & Restrita \\
\hline Agricolândia & Restrita & Inapta & Inapta & Colônia & Restrita & Plena & Restrita \\
\hline Água Branca & Restrita & Inapta & Inapta & Conceição C & Restrita & Plena & Restrita \\
\hline Alagoinha & Restrita & Plena & Restrita & Coronel J Dias & Restrita & Plena & Restrita \\
\hline Alegrete & Restrita & Plena & Restrita & Corrente & Restrita & Restrita & Inapta \\
\hline Alto Longá & Restrita & Restrita & Inapta & Cristalândia & Restrita & Restrita & Inapta \\
\hline Altos & Restrita & Inapta & Inapta & Cristino Castro & Restrita & Restrita & Restrita \\
\hline Alvorada Gurguéič & Restrita & Plena & Restrita & Curimatá & Restrita & Restrita & Restrita \\
\hline Amarante & Restrita & Inapta & Inapta & Currais & Restrita & Restrita & Restrita \\
\hline Angical & Restrita & Restrita & Inapta & Curral novo & Restrita & Restrita & Restrita \\
\hline Anísio de Abreu & Restrita & Plena & Restrita & Curralinhos & Restrita & Restrita & Inapta \\
\hline Antônio Almeida & Restrita & Restrita & Restrita & Demerval L & Restrita & Inapta & Inapta \\
\hline Aroazes & Restrita & Restrita & Inapta & D Arcoverde & Restrita & Plena & Restrita \\
\hline Arraial & Restrita & Plena & Inapta & D Expedito & Restrita & Plena & Restrita \\
\hline Assunção & Restrita & Plena & Inapta & D. Inocêncio & Restrita & Plena & Restrita \\
\hline Avelino Lopes & Restrita & Plena & Restrita & Domingos $\mathrm{M}$ & Restrita & Restrita & Restrita \\
\hline Baixa G. Ribeiro & Restrita & Plena & Inapta & Elesbão V & Restrita & Restrita & Inapta \\
\hline Barra D'Alcântara & Restrita & Plena & Inapta & Eliseu Martins & Restrita & Plena & Restrita \\
\hline
\end{tabular}


Lucena et al.

\begin{tabular}{|c|c|c|c|c|c|c|c|}
\hline Barras & Restrita & Inapta & Inapta & Esperantina & Restrita & Inapta & Inapta \\
\hline Barreiras & Restrita & Restrita & Inapta & Fartura Piauí & Restrita & Plena & Restrita \\
\hline Barro duro & Restrita & Inapta & Inapta & Flores Piauí & Restrita & Plena & Restrita \\
\hline Batalha & Restrita & Inapta & Inapta & Floresta Piauí & Restrita & Plena & Restrita \\
\hline Bela Vista & Restrita & Plena & Inapta & Floriano & Restrita & Restrita & Restrita \\
\hline Belém do Piauí & Restrita & Plena & Restrita & Francinópolis & Restrita & Inapta & Inapta \\
\hline Beneditinos & Restrita & Inapta & Inapta & Fran. Ayres & Restrita & Restrita & Restrita \\
\hline Bertolinia & Restrita & Restrita & Restrita & Franc Macedo & Restrita & Restrita & Restrita \\
\hline Betania & Restrita & Restrita & Restrita & Franc Santos & Restrita & Plena & Restrita \\
\hline Bocaina & Restrita & Plena & Restrita & Fronteiras & Restrita & Plena & Restrita \\
\hline Bom Jesus & Restrita & Restrita & Restrita & Geminiano & Restrita & Plena & Inapta \\
\hline Bom princípio & Restrita & Restrita & Restrita & Gilbués & Restrita & Restrita & Restrita \\
\hline Bonfim do Piauí & Restrita & Plena & Restrita & Guadalupe & Restrita & Inapta & Inapta \\
\hline Boqueirão & Restrita & Restrita & Inapta & Guaribas & Restrita & Restrita & Restrita \\
\hline Brasileira & Restrita & Inapta & Inapta & H. Napoleão & Restrita & Restrita & Inapta \\
\hline Brejo do Piauí & Restrita & Inapta & Restrita & Ilha grande & Restrita & Restrita & Inapta \\
\hline Buriti dos Lopes & Restrita & Restrita & Inapta & Inhuma & Restrita & Restrita & Restrita \\
\hline Buriti Montes & Restrita & Restrita & Inapta & Ipiranga Piauí & Restrita & Plena & Restrita \\
\hline Cabeceiras & Restrita & Inapta & Inapta & Isaías Coelho & Restrita & Plena & Restrita \\
\hline Cajazeiras & Restrita & Plena & Restrita & Itainópolis & Restrita & Plena & Restrita \\
\hline Cajueiro Praia & Restrita & Restrita & Inapta & Itaueiras & Restrita & Restrita & Restrita \\
\hline Caldeirão Grande & Restrita & Plena & Restrita & Jacobina Piauí & Restrita & Plena & Restrita \\
\hline Campinas & Restrita & Plena & Restrita & Jaicós & Restrita & Plena & Restrita \\
\hline C. A.Fidalgo & Restrita & Restrita & Restrita & Jardim Mulato & Restrita & Restrita & Inapta \\
\hline Campo Grande & Restrita & Plena & Restrita & Jatobá Piauí & Restrita & Restrita & Inapta \\
\hline Campo Largo & Restrita & Inapta & Inapta & Jerumenha & Restrita & Restrita & Restrita \\
\hline Campo Maior & Restrita & Inapta & Inapta & João Costa & Restrita & Plena & Restrita \\
\hline Canavieira & Restrita & Plena & Restrita & Joaquim Pires & Restrita & Inapta & Inapta \\
\hline Canto Burití & Restrita & Plena & Restrita & Joca Marques & Restrita & Plena & Inapta \\
\hline Capitão Campos & Restrita & Inapta & Inapta & José de Freitas & Restrita & Inapta & Inapta \\
\hline Cap Ger Oliveira & Restrita & Plena & Restrita & Juazeiro Piauí & Restrita & Restrita & Restrita \\
\hline Caracol & Restrita & Plena & Restrita & Júlio Borges & Restrita & Plena & Restrita \\
\hline Caraubas & Restrita & Restrita & Inapta & Jurema Piauí & Restrita & Plena & Restrita \\
\hline Caridade & Restrita & Restrita & Restrita & Lagoa Alegre & Restrita & Inapta & Inapta \\
\hline Castelo Piauí & Restrita & Restrita & Inapta & L.Francisco & Restrita & Restrita & Inapta \\
\hline Caxingó & Restrita & Restrita & Inapta & Lagoa Barro & Restrita & Plena & Restrita \\
\hline Cocal & Restrita & Restrita & Inapta & Lagoa Piauí & Restrita & Restrita & Inapta \\
\hline Cocal Telha & Restrita & Plena & Inapta & Lagoa Sítio & Restrita & Plena & Restrita \\
\hline Cocal Alves & Restrita & Plena & Restrita & Lagoinha & Restrita & Plena & Inapta \\
\hline Coivaras & Restrita & Restrita & Inapta & Landri Sales & Restrita & Inapta & Inapta \\
\hline Luzilândia & Restrita & Inapta & Inapta & R. Gonçalves & Restrita & Restrita & Inapta \\
\hline Madeiro & Restrita & Restrita & Inapta & Rio Grande & Restrita & Plena & Restrita \\
\hline Manoel Emídio & Restrita & Plena & Restrita & Santa Cruz & Restrita & Plena & Restrita \\
\hline Marcolândia & Restrita & Plena & Restrita & S. C Milagres & Restrita & Restrita & Inapta \\
\hline Marcos Parente & Restrita & Restrita & Restrita & S. Filomena & Restrita & Inapta & Inapta \\
\hline Massapê do Piauí & Restrita & Restrita & Restrita & Santa Luz & Restrita & Plena & Restrita \\
\hline Matias Olímpio & Restrita & Inapta & Inapta & Santana & Restrita & Plena & Restrita \\
\hline Miguel Alves & Restrita & Inapta & Inapta & Santa rosa & Restrita & Restrita & Restrita \\
\hline Miguel Leão & Restrita & Inapta & Inapta & S. A. Milagres & Restrita & Plena & Inapta \\
\hline Milton Brandão & Restrita & Plena & Restrita & S. A. Lisboa & Restrita & Plena & Restrita \\
\hline $\begin{array}{c}\text { Monsenhor Gil } \\
\end{array}$ & Restrita & Inapta & Inapta & Santo Inácio & Restrita & Plena & Restrita \\
\hline Mons.Hipólito & Restrita & Plena & Restrita & São Braz & Restrita & Plena & Restrita \\
\hline Monte Alegre & Restrita & Restrita & Restrita & São Félix & Restrita & Inapta & Inapta \\
\hline Morro Cabeça & Restrita & Restrita & Restrita & S. F. Assis & Restrita & Plena & Restrita \\
\hline Morro Chapéu & Restrita & Plena & Inapta & São Francisco & Restrita & Restrita & Restrita \\
\hline Murici Portelas & Restrita & Restrita & Inapta & S. Gonçalo G. & Restrita & Restrita & Inapta \\
\hline N. S. Nazaré & Restrita & Plena & Inapta & S. Gonçalo & Restrita & Restrita & Inapta \\
\hline N. S. dos Remédios & Restrita & Inapta & Inapta & j. J.Canabrava & Restrita & Plena & Restrita \\
\hline Nazária & Restrita & Restrita & Inapta & S. J. da Serra & Restrita & Restrita & Inapta \\
\hline Nova S.Rita & Restrita & Restrita & Restrita & S. J. Varjota & Restrita & Plena & Inapta \\
\hline Novo oriente & Restrita & Restrita & Restrita & S. J. do Arraial & Restrita & Inapta & Inapta \\
\hline Novo S. Antônio & Restrita & Restrita & Inapta & São João & Restrita & Plena & Restrita \\
\hline Oeiras & Restrita & Restrita & Restrita & S.J. do Divino & Restrita & Inapta & Inapta \\
\hline Olho D’Água & Restrita & Plena & Inapta & S.J. do Peixe & Restrita & Restrita & Restrita \\
\hline Padre Marcos & Restrita & Plena & Restrita & São José & Restrita & Plena & Restrita \\
\hline Paes Landim & Restrita & Plena & Restrita & São Julião & Restrita & Plena & Restrita \\
\hline Pajeu & Restrita & Restrita & Restrita & São Lourenço & Restrita & Plena & Restrita \\
\hline Palmeira & Restrita & Plena & Restrita & São Luís & Restrita & Restrita & Restrita \\
\hline Palmeirais & Restrita & Inapta & Inapta & S. M. BGrande & Restrita & Restrita & Inapta \\
\hline Paquetá & Restrita & Restrita & Restrita & S. M.l Fidalgo & Restrita & Restrita & Restrita \\
\hline Parnaguá & Restrita & Restrita & Inapta & S. M. Tapuio & Restrita & Plena & Restrita \\
\hline Parnaíba & Restrita & Inapta & Inapta & São Pedro & Restrita & Inapta & Inapta \\
\hline
\end{tabular}




\begin{tabular}{|c|c|c|c|c|c|c|c|}
\hline Pass. Franca & Restrita & Plena & Inapta & S. R Nonato & Restrita & Plena & Restrita \\
\hline Patos do Piauí & Restrita & Plena & Restrita & Sebast Barros & Restrita & Restrita & Inapta \\
\hline Pau Darco & Restrita & Restrita & Restrita & Sebastião Leal & Restrita & Plena & Inapta \\
\hline Paulistana & Restrita & Plena & Restrita & Sig Pacheco & Restrita & Plena & Inapta \\
\hline Pavussu & Restrita & Restrita & Restrita & Simões & Restrita & Plena & Restrita \\
\hline Pedro II & Restrita & Inapta & Inapta & Simplício & Restrita & Plena & Inapta \\
\hline Pedro Laurentino & Restrita & Plena & Restrita & Socorro d & Restrita & Plena & Restrita \\
\hline Picos & Restrita & Plena & Restrita & Sussuapara & Restrita & Plena & Inapta \\
\hline Pimenteiras & Restrita & Plena & Restrita & Tamboril & Restrita & Plena & Restrita \\
\hline Pio IX & Restrita & Plena & Restrita & Tanque & Restrita & Plena & Inapta \\
\hline Piracuruca & Restrita & Inapta & Inapta & Teresina & Restrita & Inapta & Inapta \\
\hline Piripiri & Restrita & Inapta & Inapta & União & Restrita & Inapta & Inapta \\
\hline Porto & Restrita & Inapta & Inapta & Uruçuí & Restrita & Inapta & Inapta \\
\hline Porto Alegre & Restrita & Restrita & Inapta & Valença & Restrita & Restrita & Inapta \\
\hline Prata do Piauí & Restrita & Inapta & Inapta & Várzea Branca & Restrita & Plena & Restrita \\
\hline QueimadaNova & Restrita & Plena & Restrita & Várzea Grande & Restrita & Inapta & Inapta \\
\hline Redenção Gurguéi & Restrita & Plena & Restrita & Vera Mendes & Restrita & Restrita & Restrita \\
\hline Regeneração & Restrita & Inapta & Inapta & Vila Nova & Restrita & Restrita & Restrita \\
\hline Riacho Frio & Restrita & Plena & Restrita & Wall Ferraz & Restrita & Restrita & Restrita \\
\hline
\end{tabular}

\section{CONCLUSÕES}

Para o estado do Piauí as atividades fisiológicas da palma forrageira são bastantes restritas devido às condições inadequadas da disponibilidade de temperatura e do índice de umidade, como foi verificado em todos os municípios do Estado, que se apresentaram dentro da faixa restrita ou inapta ao desenvolvimento da cultura, apesar de que, Acauã, Alagoinha, Alegrete, Alvorada Gurguéia, Anísio de Abreu, Assunção, Avelino Lopes, Baixa G. Ribeiro, Barra D'Alcântara, Bela Vista, Belém do Piaú, Bocaina, Bonfim do Piauí, Cajazeiras, Isaías Coelho, Itainópolis, Ipiranga Piauí, Franc Santos, Fronteiras, Geminiano, Fartura Piauí, Flores Piauí Floresta Piauí, Eliseu Martins, Colônia G., Colônia Piauí, Conceição C, Coronel J Dias, D Arcoverde, D Expedito, D. Inocêncio, Caldeirão Grande, Campinas Piauí, Canavieira, Canto Burití, Caracol, Cocal Telha, Cocal Alves, Manoel Emídio, Marcolândia, Milton Brandão, Monsenhor Hipólito, Morro Chapéu Piauí, Nossa S. Nazaré, Olho D’Água, Padre Marcos, Paes Landim, Palmeira Piauí, Passagem Franca, Patos do Piauí, Paulistana, Pedro Laurentino, Picos, Pimenteiras Piauí, Pio IX, Piracuruca, Queimada Nova, Redenção Gurguéia, Várzea Branca, Sebastião Leal, Sigefredo Pacheco, Simões, Simplício Mendes, Socorro do Piauí, Sussuapara, Tamboril do Piauí, São José do Piauí, São Julião, São Lourenço, São João do Piauí, São João da Varjota, S. João Canabrava, S. João Fronteira,
S. Antônio Milagres, S. Antônio Lisboa, Santo Inácio, São Braz, Santa Luz, Santana, Rio Grande, Santa Cruz do Piauí, Lagoa Sítio, Lagoinha, Lagoa Barro, Júlio Borges, Jurema Piauí, Joca Marque, João Costa, Jacobina Piauí, Jaicós, disponibilizam de índices pluviométricos necessários ao bom desenvolvimento.

Para o plantio em larga escala é necessário um planejamento adequado para a utilização de cultivares mais resistentes as temperaturas e os índices de umidade, e adequação de sistema de irrigação eficiente e compatível com a demanda de água da cultura.

\section{REFERÊNCIAS BIBLIOGRÁFICAS}

ARAÚJO, L.F.; OLIVEIRA, L.S.C. Equilíbrio higroscópico da palma forrageira: Relação com a umidade ótima para fermentação sólida. Revista Brasileira de Engenharia Agrícola e Ambiental, vol.9. n 3. P.379-384. 2005.

BEZERRA, B.G.; ARAÚJO, J.S.; PEREIRA, D.D.; LAURENTINO, G.Q.; SILVA, L.L. Zoneamento agroclimático da palma forrageira (Opuntia sp.) para o estado da Paraíba. Revista Brasileira de Engenharia Agrícola e Ambiental, v. 18, n. 7, p. 755-761, 2014.

CAMARGO, A.P. Balanço hídrico no Estado de São Paulo. Campinas: IAC, p.28. (Boletim Técnico, 116). 1971. 
CAVALCANTI, E.P.; SILVA, V.P.R.; SOUSA, F.A.S. Programa computacional para a estimativa da temperatura do ar para a Região Nordeste do Brasil. Revista Brasileira de Engenharia Agrícola e Ambiental, v.10, n.1, p.140-147, 2006.

CONDEPI. Companhia do desenvolvimento do Estado do Piaúi. 2000.

GUERRA, M.G.; MAIA, M.O.; MEDEIROS, H.R.; LIMA, G.F.C.; AGUIAR, E.M.; GARCIA, L.R.U.C. Produção de novos genótipos de palma forrageira no Estado do Rio Grande do Norte. In: 42 ${ }^{\mathrm{a}}$ Reunião Anual da Sociedade Brasileira de Zootecnia, 2005, Goiânia-GO. Anais... CD-ROM, Goiânia-GO, 2005.

HORIKOSHI, A.S.; FISCH, G. Balanço Hídrico Atual e Simulações para Cenários Climáticos Futuros no Município de Taubaté, SP, Brasil. Revista Ambiente e Água - An Interdisciplinary Journal of Applied Science, v.2. n.2. 2007.

KAYANO, M.T.; ANDREOLI, R. Variabilidade decenal e multidecenal, In: Cavancanti, I.; Ferreira, N.; Silva, M. G. J. da; Dias, M. A. F. S. (ed.). Tempo e Clima no Brasil, Oficina de Textos, Sao Paulo. p. 375383. 2009.

MARENGO, J. A. Vulnerabilidade, Impactos e adaptação as mudança de clima no semiárido do Brasil. In Parcerias Estrategicas/Centro de Gestão de Estudos Estratégicos-Ministerio da Ciencia e Tecnologia, v.1, n.1, Braslia DF, p. 149-176, 2009.

MARENGO, J.A.; ALVES, L.M.; BESERRA, E.A.; LACERDA, F.F. Variabilidade e mudanças climáticas no semiárido brasileiro. Instituto Nacional do Semiárido: Campina Grande-PB, 2011. Disponível em: $<$ http://plutao.sid.inpe.br/col/dpi.inpe.br/plutao/ 2011/06.11.02.16/doc/Marengo_Variabilidade. pdf?languagebutton $=\mathrm{en}>$. Acesso em: 10.fev.2016.
MARENGO, J.A.; SOARES, W.R.; SAULO, C.; NICOLINI, M. Climatology of the lowlevel Jet East of the Andes as Derived from NCEP-NCAR Reanalyses: Characteristics and Temporal Variability. Journal of Climate, v. 17, n. 12, p. 2261 - 2280, 2004.

MEDEIROS, R.M.; MATOS, R. M.; SILVA, P.F.; SILVA, J.A.S. FRANCISCO, P.R.M. Caracterização climática e diagnóstico da aptidão agroclimática de culturas para Barbalha - CE. Revista Enciclopédia Biosfera, v. $11 \mathrm{n}$. 21; p. 461-476, 2015.

MEDEIROS, R.M.; SILVA, J.A.S.; SILVA, A.O.; MATOS, R.M.; BALBINO, D.P. Balanço hídrico climatológico e classificação climática para a área produtora da banana do município de Barbalha, CE. Revista Brasileira de Agricultura Irrigada, v. 7, n. 4, p. 258 268, 2013.

MEDEIROS, R.M. Elaboração de programa computacional em planilhas eletrônicas do Balanço hídrico. 2014.

MEDEIROS, R.M.; SANTOS, D.C.; SOUSA, F.A.S.; GOMES FILHO, M.F. Análise Climatológica, Classificação Climática e Variabilidade do Balanço Hídrico Climatológico na Bacia do Rio Uruçuí Preto, PI. Revista Brasileira de Geografia Física. Recife - PE, v.6, p.652-664, 2013.

MOURA, M.S.B.; SOUZA, L.S.B.; SILVA, T.G.F.; SÁ, I.I.S. Zoneamento agroclimático da palma forrageira para 0 estado de Pernambuco. Petrolina: Embrapa Semiárido. 26p. Documentos 242. 2011.

NOBRE, P.; MELO, A.B.C. Variabilidade climática intra-sazonal sobre o Nordeste do Brasil em 1998 - 2000. Climanálise, CPTEC/INPE, São Paulo. 2001.

OLIVEIRA NETO, S.N.; REIS, G.G.; REIS, M.G.F.; LEITE, H.G.; COSTA, J.M.N. Estimativa de temperaturas mínima, média e máxima do território brasileiro situado entre 16 e $24^{\circ}$ latitude sul e 48 e $60^{\circ}$ longitude oeste. 
Engenharia na Agricultura, Viçosa, MG, v. 10, n. 1-4, p. 57-61, 2002.

OMETTO, J. C. Bioclimatologia vegetal. São

Paulo: Ceres, 1981.

PEREIRA, A.R.; ANGELOCCI, L.R.; SENTELHAS, P.C. Agrometeorologia: fundamentos e aplicações práticas. Guaíba: Livraria e Editora Agropecuária, p.478, 2002.

PINTO, S.A.; ASSAD, E.D.; ZULLO JÚNIOR, J.; ÁVILA, A.M.H. Variabilidade climática. In: HAMADA, E. (Ed.). Água, agricultura e meio ambiente no Estado de São Paulo: avanços e desafios. Jaguariúna: Embrapa Meio Ambiente, Cap. CDROM. 2011.

ROCHA, J.E.S. Palma forrageira no Brasil: o estado da arte. EMBRAPA Caprinos e Ovinos. 40p. (Documentos, 106). 2012.

SANTOS, A.S.; GOMES, H.B.; AMORIM, R.F.C.; AMORIM, R.C.F.; PONTES, E.G.S.; MEDEIROS, F.C. Estudo da Climatologia dos Ventos Através dos Dados de Reanálises: Período 1970-2002, e Sua Relação com a Precipitação para o Estado de Alagoas nos Anos 1992/94. In: XIII Congresso Brasileiro de Meteorologia, 2001, Fortaleza - CE. Meteorologia e o Desenvolvimento Sustentável, 2001.

SANTOS, G.O.; HERNANDEZ, F.B.T.; ROSSETTI, J.C. Balanço hídrico como ferramenta ao planejamento agropecuário para a região de Marinópolis, noroeste do estado de São Paulo. Revista Brasileira de Agricultura Irrigada, v. 4, n. 3, p.142 - 149, 2010.

SILVA, J.A.S.; MEDEIROS, R.M.; SILVA, A.O.; SILVA, J.W.O.S.; MATOS, R.M. Oscilações no regime da precipitação pluvial no município de Barbalha - CE. In: I Simpósio Brasileiro de Recursos Naturais do Semiárido -
SBRNS, Iguatu - CE, Brasil. 2006.

SOUZA, L.S.B.; MOURA, M.S.B.; SILVA, T.G.F.; SOARES, J.M.; CARMO, J.F.A.; BRANDÃO, E.O. Indicadores climáticos para o zoneamento agrícola da palma forrageira (Opuntia sp.). In: Jornada de Iniciação Científica da Embrapa Semiárido, 3, Petrolina. Anais...Petrolina: Embrapa Semi-Árido, 2008. p.23-28. 2008.

SUDENE - Superintendência de Desenvolvimento do Nordeste. Dados pluviométricos mensais do Nordeste - Piauí. Recife, 1990 (Série Pluviometria, 2).

PINTO, T. F.; COSTA, R. G.; MEDEIROS, A. N. DE; MEDEIROS, G. R.; AZEVEDO, P. S.; OLIVEIRA, R. L.; TREVIÑO, I. H. Use of cactus pear (Opuntia ficus indica Mill) replacing corn on carcass characteristics and non-carcass components in Santa Inês lambs. Revista Brasileira de Zootecnia, v.40, p.13331338, 2011.

THORNTHWAITE, C.W.; MATHER, J.R. The water balance. Publication in Climatology. n 8, Laboratory of Climatology, Centerton, N. J. 1955.

TOLEDO, J.V.; MARTINS, L.D.; KLIPPEL, V.H.; PEZZOPANE, J.E.M.; TOMAZ, M.A.; AMARAL, J.F.T. Zoneamento agroclimático para a cultura do pinhão manso (Jatropha CurcasL.) e da mamona (Ricinus Communis L.) no estado do Espírito Santo. Agropecuária Científica no Semi-Árido, v. 05, p. 41 - 51, 2009.

UNESCO. Mexico City Declaration on Cultural Policies World Conference on Cultural Policies Mexico City, 26 July - 6 August, 1982.

WOLLMANN, C.A.; GALVANI, E. Zoneamento agroclimático: linhas de pesquisa e caracterização teórica-conceitual. Sociedade e Natureza, v. 25, p. 179-190, 2013. 